See discussions, stats, and author profiles for this publication at: https://www.researchgate.net/publication/224638878

\title{
The Educational Modeling of a Collaborative Game using MOT+LD
}

Conference Paper · August 2006

DOI: 10.1109/ICALT.2006.1652670 · Source: IEEE Xplore

CITATIONS

11

2 authors:

Gilbert Paquette

Télé-université

91 PUBLICATIONS 1,441 CITATIONS

SEE PROFILE
READS

72

Michel Léonard

Télé-université

26 PUBLICATIONS 424 CITATIONS

SEE PROFILE 


\title{
The Educational Modeling of a Collaborative Game using MOT+LD
}

\author{
Gilbert Paquette and Michel Léonard \\ CICE Research Chair, LICEF Research Center, Télé-université \\ gilbert.paquette@licef.teluq.uqam.ca
}

\begin{abstract}
Our contribution to the workshop on educational modeling languages is a graphic model of a collaborative game. It is built using the MOT+LD graphic editor developed at our research center,

\section{The MOT+LD graphic editor}

Work on EML has started at the LICEF research center in 1992 with the design of an instructional design system called AGD. From it, a method and a series of graphic modeling editor have been built up to the MOT + LD graphic editor [1]. Figure 1 shows the basic graphic symbols in this editor that will be used to model the learning designs. These symbols cover all the IMS-LD level A primitives. To model a learning design, we just link these objects through: composition, instantiation, precedence and other relations.
\end{abstract}

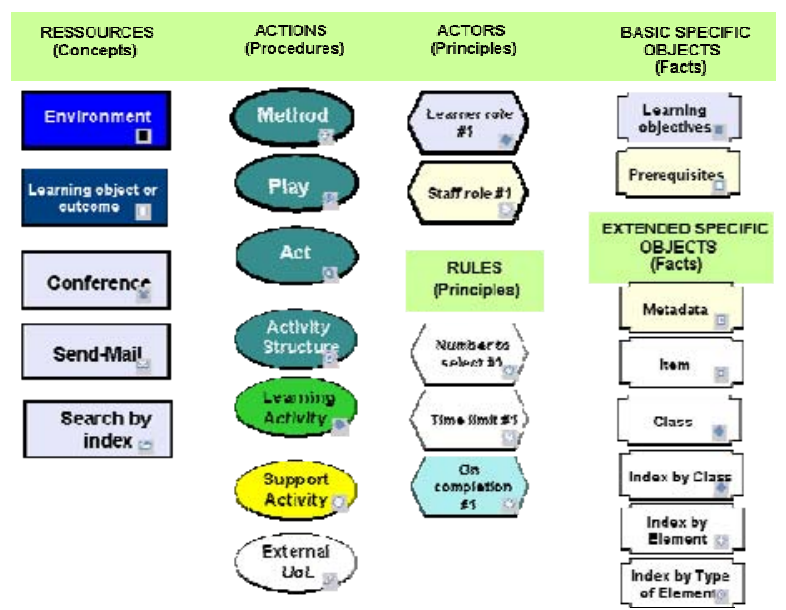

Figure 1 - Basic MOT+LD graphic symbols

\section{Modeling of the collaborative case study}

Using the IMS-LD terminology, we have divided the proposed collaborative scenario into four acts. Act1 , presented on figure 2 , is where the teacher organizes the learners in two teams and provides learners with an environment that they can start to explore: a group forum, content documents on the subject of the solar system, a graphic view of the learning scenario. Later on, a private chat will be made available to each team and a questionnaire will be filled by each learner.

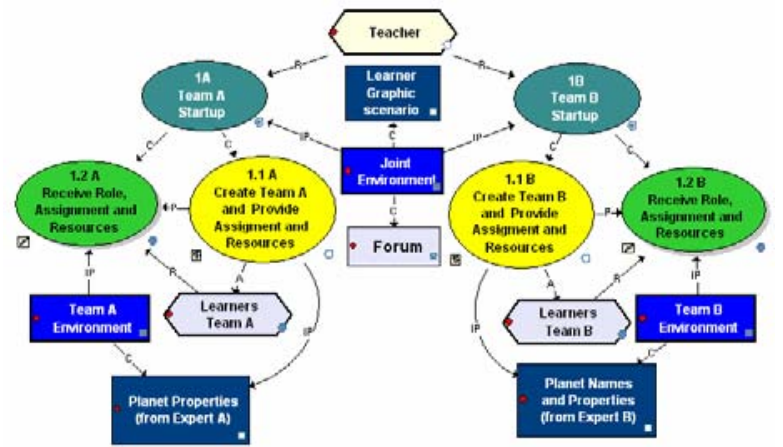

Figure 2-Act 1- Organization

Act-2, presented on figure 3, is the next step. Here learners collaborate with their team mates using a chat roam and each team collaborate with the other using the forum to find a game solution. The teacher observes, manages and moderates the forum. He can also provide additional information to a team or to both if he sees that the discussion is not progressing properly. Labels on the "action" symbols, specify the roles of participants in the forum.

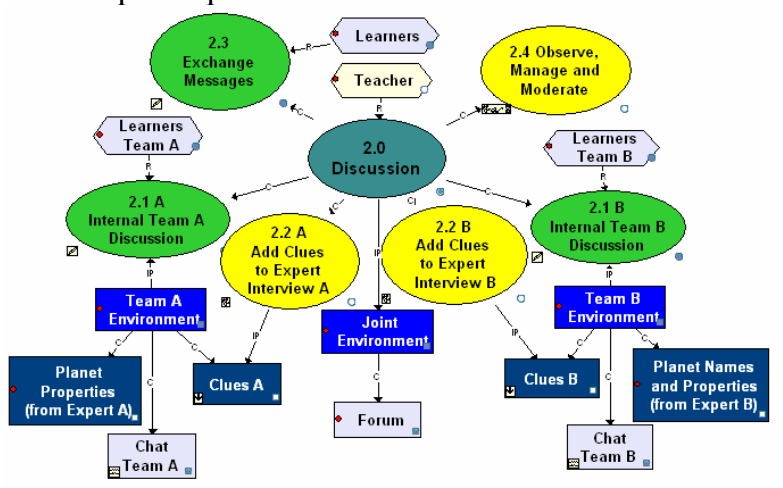

Figure 3 - Act 2- Discussion

In Act-3, as shown on figure 4, the teacher stops the discussion in the forum and provides a questionnaire to 
each individual learner to be answered and sent it the teacher using a homework upload tool.

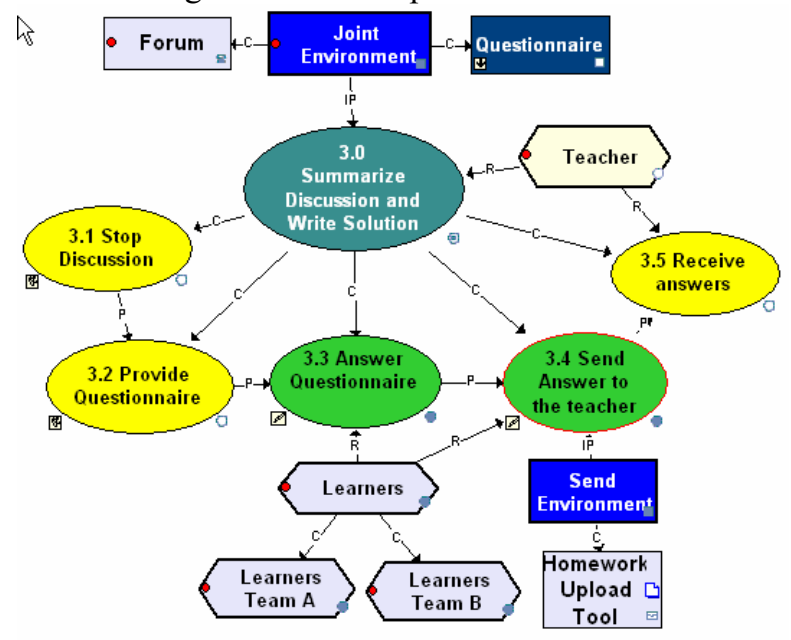

Figure 4 - Act 3- Production

Finally, in act 4 (figure 5), the play terminates when the teacher has evaluated the answers and presented the best solutions to the learners. This start a last sequence of discussion between the learners in the forum.

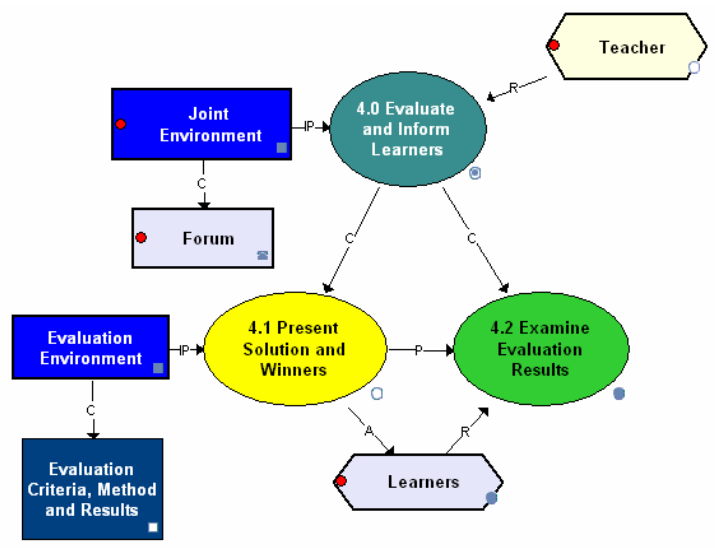

Figure 5 - Act 4- Evaluation and Feedback

\section{Itemization, Validation, Delivery}

To complete the model, we need to specify the locations of documents, tools, activity assignments, perquisites and learning objectives, and specific participants. These "items" are associated to "abstract" objects in the following manner (using an instantiation "I" link). Two examples are given below.

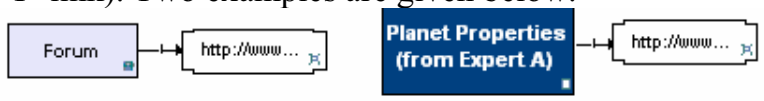

MOT + LD has a built-in function that validates the design for conformance with the IMS-LD specification and produces a corresponding IMS-LD XML file. This has been done for the model of section 2. Slight changes were detected and have been made. Then we have read back the XML file of the design into RELOAD to add level $\mathrm{B}$ and $\mathrm{C}$ conditions and properties, to synchronize operations within the acts.

Some work remains to be done to finalize the delivery of the play: finding suitable documents and tools, insert their locations in the editor and pass it on to one or more delivery platform like RELOAD PLAYER or TELOS.

\section{Conclusions}

The graphs in section 2 capture a generic representation of the method structure. Thought this unit-of learning is planned for a study of the solar system, it can be reuse for other subjects by changing document titles and associating different item locations.

The graphic design of this collaborative game was painless and required only two or three iterations between the two instructional designers (the authors). We believe that we expressed the entire narrative scenario that was provided to us.

We must point out that the narrative itself will need a few improvement. If some of the learners search the Internet during the play, they are likely to find a solution shortcutting the scenario. In the final version, we will simply modify replace items for the activities to provide different rules for the game.

Some ambiguity remains in IMS-LD in the representation of collaborative activities [2]. For example, if $\mathrm{N}$ actors are involved in role-parts within the same activity, there is yet no vocabulary to distinguish between situations where they work separately or together. In our MISA instructional engineering method [3], we have built a set of collaboration rules that could help improve the specification or be integrated into level B conditions.

\section{References}

[1] Paquette, G., M. Léonard, K. Lundgren-Cayrol, S. Mihaila and D. Gareau. (2006) Learning Design based on Graphical Knowledge-Modeling, Journal of Educational technology and Society. Special Issue in January 2006.

[2] Paquette, G., and O. Marino. (2006 to be published) Learning Objects, Collaborative Learning Designs and Knowledge Representation. Technology, Instruction, Cognition and Learning, Vol. 3, Old City Publishing, Inc.

[3] Paquette, Gilbert. (2003) Instructional Engineering for Network-Based Learning. Pfeiffer/Wiley Publishing Co. 